\title{
Salivary Glands Inflammation as Visualized with Ultrasonography
}

ISSN: 2637-7764

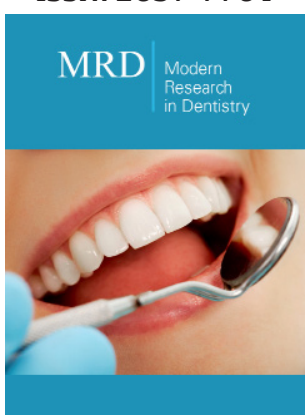

*Corresponding author: Antigoni Delantoni, DDS, MSc, PhD, MD, Aristotle University of Thessaloniki, Greece

Submission: 佂 November 05, 2019

Published: 眥 November 13, 2019

Volume 4 - Issue 4

How to cite this article: Antigoni Delantoni. Salivary Glands Inflammation as Visualized with Ultrasonography. Mod Res Dent. 4(4). MRD.000592.2019.

DOI: 10.31031/MRD.2019.04.000592

Copyright@ Antigoni Delantoni, This article is distributed under the terms of the Creative Commons Attribution 4.0 International License, which permits unrestricted use and redistribution provided that the original author and source are credited.
Antigoni Delantoni*

Aristotle University of Thessaloniki, Greece

\section{Introduction}

The major salivary glands are superficial exocrine glands that produce saliva and keep the oral cavity moist.

They are the paired parotid, submandibular, and sublingual glands. The upper aerodigestive tract mucosa is lined by hundreds of small, minor salivary glands. A connective tissue capsule surrounds the gland and extends into parenchyma, dividing the gland into groups of secretory units and ducts known as lobes and lobules. Blood vessels, lymphatic vessels and nerves that supply the gland, are present within the capsule.

As superficial anatomical structures the salivary glands are easily accessible to ultrasound. Ultrasound has several advantages that make it the examination of choice in the study of their pathology [1-5]. Main advantages are the easy accessibility and the low cost of the method, the safety of technique since radiation is avoided and the excellent image analysis in real time with the newer high frequency transducers used since they provide the details of the superficial structures required for the examination [6]. It is a technique based on sound waves that acquire images after being sent to the tissues/ The response is in real time and free of radiation [7]. Diagnostic ultrasonography is the clinical use of ultrasounds using vibratory frequencies ranging from 1 to $20 \mathrm{MHz}$ [8-10]. In the maxillofacial region high frequency transducers are needed to provide the details required in the superficial structures of the glands. Inflammation of the salivary glands of varying aetiology is the major problem occuring in the pathology of the glands which is easily and readily diagnosed with ultrasounds [11-14].

\section{Inflammatory disease (Parotitis)}

It is the most common cause of parotid swelling in developed countries. The most frequent symptom includes non-continuous pain and fever as well as unilateral or bilateral swelling of the glandular area [15-18]. The inflammation is limited only to the area of parotid gland, without involvement of the submandibular or sublingual glands thus the word parotitis in contrast to sialadenitis which could be in all glands. It is of unknown etiology in a number of cases and the differential diagnosis include mumps or the suppurative parotitis, which is easily excluded from the clinical symptoms [19-21]. The majority of cases involve children while there is episode reduction as the children grow, and they cease near puberty or in late adolescence. The male sex is more frequently affected [21-25]. For the cases of parotitis in the past, sialography was the prime modality for glandular imaging by showing punctate or globular areas of sialectasis. Ultrasound is now the favored imaging approach. Most sonograms of parotitis show the characteristic enlarged parotid glands with multiple round, hypoechoic areas measuring 2 to $4 \mathrm{~mm}$ in diameter, likely representing peripheral sialectasis and lymphocytic infiltration. The vascularity of the glands may increase secondary to the inflammation process [26-28].

\section{Other inflammatory conditions}

Chronic sialadenitis may affect all the major glands and is caused by inflammation that is not treated and rests, leading to alterations of the acini and secretory function of the glands. It is attributed to bacterial or non-bacterial inflammations [29]. Clinically the patients present with swelling and pain. Causes usually include granulomatous conditions such as actinomycosis 
and histoplasmosis. When of granulomatous etiology, they may appear with less inflammatory image features at ultrasound and demonstrate a hypo echoic mass with poorly refined margins [30]. Bacterial gland infection is more common, usually presenting at childhood with more common ages from 2-4 years of age. With the addition of color Doppler to the images due to the inflammatory origin of the pathology the lesions do not show increased color flow (which is a differential diagnostic feature from neoplasms). Other inflammatory conditions with similar ultrasonographic features are autoimmune diseases and recurrent sialolithiasis. Sjögren's syndrome is an autoimmune disorder that results in inflammation and destruction of the exocrine glands, primary the lacrimal and salivary glands. To avoid irradiating the patient at follow ups it is preferable to monitor them with ultrasound.

\section{Inflammation from drainage failure due to calcification (salivary stone or sialolithiasis)}

The most common reason for inflammation of a single salivary gland is in $80 \%$ of cases the presence of a sialolith. Salivary stones form usually within the duct of the glands with more frequent the Wharton's duct of the submandibular gland [31]. They are hard stone like structures, that form within the gland. They are made of mineral stones, they are slow in development and they may block the ductal system of the gland. When this happens, the drainage of the gland is blocked, the patient demonstrates pain and swelling and inflammatory features of the glandular system [32]. With the use of ultrasound, the calculus may be readily visible, but in many cases the acoustic shadow of the stone may be all that is visualized. The use of ultrasound is crucial since it visualizes the glandular parenchyma easily [33].

Sjögren's syndrome and other autoimmune disease, including HIV, are at risk for primary lymphoma. It involves all exocrine glands and the primary diagnostic symptoms are usually from the eyes with decrease of lacrimal glands excretions. Ultrasonographic features include a generalized diffused image with infiltration and full gland involvement which results to an enlarged gland. Lesions may consist of multiple small, hypoechoic nodules or an irregularly shaped, heterogeneous mass without calcification or anechoic cystic degeneration. The imaging features are similar to lymphomas and /or adenitis. Some authors in chronic conditions describe the presence of hypoechoic compartments surrounded by hyperechoic lines, creating a tortoiseshell appearance. Increased color and Doppler flow are typical. In the majority of cases the disease appears on patients with known autoimmune history. To conclude one must mention the ultrasonography in the maxillofacial region is not frequently applied. However with the advances in the ultrasonographic probes and transducers its appllications are increasing and it should be used at an examination method in the cases of soft tissue involvement since in a number of cases it solves problems and provides diagnosis.

\section{References}

1. Buddemeyer EU (1975) The physics of diagnostic ultrasound. Radiol Clin North Am 13(3): 391-402.
2. Noce JP (1990) Fundamentals of diagnostic ultrasonography. Biomed Instrum Technol 24(6): 456-459.

3. Gooding AW (1980) Gray scale ultrasonography of the neck. JAMA 243(15): 1562-1564.

4. Binholz JC (1973) Sonic differentiation of cysts and homogenous solid masses. Radiology 108(3): 699-702.

5. Chodosh PL, Silbey R, Oen KT (1980) Diagnostic use of ultrasound in diseases of head and neck. Laryngoscope 90(5 Pt 1): 814-821.

6. Gooding GA (1980) Gray scale ultrasound of the parotid gland. AJR Am J Roentgenol 134(3): 469-472.

7. Gritzmann N (1989) Sonography of the salivary glands. Am J Roentgonol 153(1): 161-166

8. Nelson TR, Fowlkes JB, Abramowicz JS, Church CC (2009) Ultrasound biosafety considerations for the practicing sonographer and sonologist. J Ultrasound Med 28(2): 139-150.

9. Yoshimura Y, Inove Y, Odagawa T (1989) Sonographic examination of sialolithiasis. J Oral Maxillofac Surg 47(9): 907-912.

10. Bruneton JN, Fenart D, Vallicioni J, Demard F (1980) Ultrasonic findings of parotid tumors in 40 patients. J Radiol 61(3): 151-154.

11. Katz P, Hartl DM, Guerre A (2009) Clinical ultrasound of the salivary glands. Otolaryngol Clin North Am 42(6): 973-1000.

12. Magaram D, Gooding GA (1981) Ultrasonic guided aspiration of parotid abscess. Arch Otolaryngol 107(9): 549.

13. Yuasa K, Kawazu T, Nagata T, Kanda S, Ohishi M, et al. (2000) Computed tomography and ultrasonography of metastatic cervical lymph nodes in oral squamous cell carcinoma. Dentomaxillofac Radiol 29: 238-244.

14. Luigi S, Vincenzo C (2000) Ultrasonography of the neck. Radiol Clin North Am 38(5): 1029-1045.

15. Wakasugi Sato N, Kodama M, Kou M, Noriaki Y, Masafumi O, et al. (2010) Advanced clinical usefulness of ultrasonography for diseases in oral and maxillofacial regions. Int J Dent p. 10.

16. Bozzato A, Zenk J, Greess H, Hornung J, Gottwald F, et al. (2007) Potential of ultrasound diagnosis for parotid tumors: analysis of qualitative and quantitative parameters. Otolaryngol Head Neck Surg 137(4): 642-646.

17. Bhatia KS, Rasalkar DD, Lee YP, Wong KT, King AD, et al. (2010) Evaluation of real-time qualitative sonoelastography of focal lesions in the parotid and submandibular glands: Applications and limitations. Eur Radiol 20(8): 1958-1964.

18. Lee YY, Wong KT, King AD, Ahuja AT (2008) Imaging of salivary gland tumours. Eur J Radiol 66(3): 419-436.

19. Herman J, Sedlackova Z, Vachutka J (2017) Differential diag- nosis of parotid gland tumors: role of shear wave elastography. Biomed Res Int p. 6.

20. Cantisani V, David E, De Virgilio A, Sidhu PS, Grazhdani H, et al. (2017) Prospective evaluation of Quasistatic Ultrasound Elastography (USE) compared with baseline US for parotid gland lesions: preliminary results of elasticity contrast index (ECI) evaluation. Med Ultrason 19(1): 32-38.

21. Klintworth N, Mantsopoulos K, Zenk J, Psychogios G, Iro H, et al. (2012) Sonoelastography of parotid gland tumours: Initial experience and identification of characteristic patterns. Eur Radiol 22(5): 947-956.

22. Gietka Czernel M, Kochman M, Bujalska K, Stachlewska NE, Zgliczynski W (2010) Real-time ultrasound elastography - a new tool for diagnosing thyroid nodules. Endokrynol Pol 61(6): 652-657.

23. Bhatia KS, Tong CS, Cho CC, Yuen EH, Lee YY, et al. (2012) Shear wave elastography of thyroid nodules in routine clinical prac- tice: preliminary observations and utility for detecting malignancy. Eur Radiol 22(11): 2397-2406. 
24. Evans A, Whelehan P, Thomson K, Brauer K, Jordan L, et al (2012) Differentiating benign from malignant solid breast masses: value of shear wave elastography according to lesion stiffness combined with greyscale ultrasound according to BI-RADS classification. Br J Cancer 107(2): 224-229.

25. Pinto F, Totaro A, Calarco A, Sacco E, Volpe A, et al (2011) Imaging in prostate cancer diagnosis: present role and future perspectives. Urol Int 86(4): 373-382.

26. Seitz M, Strittmatter F, Roosen A, Tilki D, Gratzke C (2010) Current status of ultrasound imaging in prostate cancer. Panminerva Med 52(3): 189194.

27. Mahdavi SS, Moradi M, Wen X, Morris WJ, Salcudean SE (2011) Evaluation of visualization of the prostate gland in vibro- elastography images. Med Image Anal 15(4): 589-600.

28. Altinbas NK, Anamurluoglu EG, Oz II, Yuce C, Yagci C, et al (2017) Realtime sonoelastography of parotid gland tumors. J Ultrasound Med 36(1) 77-87.
29. Badea AF, Bran S, Tamas Szora A, Floareş A, Badea R, et al. (2013) Solid parotid tumors: an individual and integrative analysis of various ultrasonographic criteria. A prospective and observational study. Med Ultrason 15(4): 289-298.

30. Celebi I, Mahmutoglu AS (2013) Early results of real-time qualitative sonoelastography in the evaluation of parotid gland masses: A study with histopathological correlation. Acta Radiol 54(1): 35-41.

31. Mansour N, Bas M, Stock KF, Strassen U, Hofauer B, et al. (2017) Multimodal ultrasonographic pathway of parotid gland le- sions. Ultraschall Med 38(2): 166-173.

32. Wierzbicka M, Kałuzny J, Szczepanek Parulska E, Stangierski A, Gurgul E, et al. (2013) Is sonoelastography a helpful method for evaluation of parotid tu- mors? Eur Arch Otorhinolaryngol 270(7): 2101-2107.

33. Yu J, Du Y, Lu Y, Zhang W, Zhang D, et al. (2016) Application of DTI and ARFI imaging in differential diagnosis of parotid tumours. Dentomaxillofac Radiol 45(6): 20160100. 